\title{
Highly syndioselective coordination (co)polymerization of para-chlorostyrene
}

Yi Wu ${ }^{\dagger,+, \perp}$ Zichuan Wang, ${ }^{\S, \perp}$ Dongtao Liu, ${ }^{\dagger}$ Bo Liu ${ }^{*,+, \downarrow}$ and Dongmei Cui ${ }^{*, \dagger, \downarrow}$

\section{Contents}

Experimental Procedures.

Table S1. NBO analysis of the charge for each carbon in para-chlorostyrene and styrene.

Figure S1. ${ }^{1} \mathrm{H}$ NMR spectrum $\left(400 \mathrm{MHz}, \mathrm{C}_{6} \mathrm{Cl}_{2} \mathrm{D}_{4}, 110^{\circ} \mathrm{C}\right)$ of a syndioselective $\operatorname{poly}(p \mathrm{CS})$ (Table 1, entry 13).

Figure S2. ${ }^{13} \mathrm{C}$ NMR spectrum $\left(500 \mathrm{MHz}, \mathrm{C}_{4} \mathrm{D}_{8} \mathrm{O}, 25^{\circ} \mathrm{C}\right)$ of a syndioselective poly $(p \mathrm{CS})$ (Table 1, entry 13).

Table S2. Homopolymerizations of $p \mathrm{CS}$ in various solvents by complex $\mathbf{3}$.

Figure S3. Representative DSC curve of syndiotactic P( $p C S)$ (Table 1, entry 13).

Figure S4. ${ }^{1} \mathrm{H}$ NMR spectra $\left(500 \mathrm{MHz}, \mathrm{CDCl}_{3}, 25^{\circ} \mathrm{C}\right)$ of $p \mathrm{CS}-\mathrm{St}$ copolymers (Table 2, runs 1-5).

Figure S5. ${ }^{13} \mathrm{C}$ NMR spectrum $\left(500 \mathrm{MHz}, \mathrm{CDCl}_{3}, 25^{\circ} \mathrm{C}\right)$ of $p \mathrm{CS}-\mathrm{St}$ copolymer (Table 2, run 1).

Figure S6. GPC curve of $p$ CS-St copolymer (Table 2, run 1).

Figure S7. GPC curve of $p$ CS-St copolymer (Table 2, run 2).

Figure S8. GPC curve of $p$ CS-St copolymer (Table 2, run 3). 
Figure S9. GPC curve of $p$ CS-St copolymer (Table 2, run 4).

Figure S10. GPC curve of $p$ CS-St copolymer (Table 2, run 5).

Table S3. Copolymerizations of $p \mathrm{CS}$ with styrene under low conversion $(<10 \%)$.

Figure S11. The reactivity ratio of styrene and para-chlorostyrene.

Figure S12. ${ }^{1} \mathrm{H}$ NMR spectrum $\left(500 \mathrm{MHz}, \mathrm{CDCl}_{3}, 25^{\circ} \mathrm{C}\right)$ of $p \mathrm{CS}-\mathrm{St}-\mathrm{BD}$ terpolymer (Table 3, run 4).

Figure $\mathrm{S} 13 .{ }^{13} \mathrm{C}$ NMR spectrum $\left(500 \mathrm{MHz}, \mathrm{CDCl}_{3}, 25^{\circ} \mathrm{C}\right)$ of $p \mathrm{CS}-\mathrm{St}-\mathrm{BD}$ terpolymer (Table 3, run 4). 


\section{Experimental Procedures}

General Methods. All manipulations were performed under a dry and oxygen-free nitrogen atmosphere using standard high-vacuum Schlenk techniques or in a glovebox. All solvents were purified with a SPS system. Styrene and para-chlorostyrene $(p C S)$ were purchased from Energy Chemical, dried by stirring with $\mathrm{CaH}_{2}$ for $72 \mathrm{~h}$ and distilled before use. Complexes1-3 were prepared according to the literature. ${ }^{1}\left[\mathrm{Ph}_{3} \mathrm{C}\right]\left[\mathrm{B}\left(\mathrm{C}_{6} \mathrm{~F}_{5}\right)_{4}\right]$ was synthesized following the literature. ${ }^{2}$

The NMR data of the $p \mathrm{CS}$ homopolymers and the $p \mathrm{CS}-\mathrm{St}$ copolymers were obtained on a Bruker AV500 or Bruker AV400 spectrometer in 1,1,2,2-tetrachloroethane-d2 (syndiotactic $p \mathrm{CS}$ homopolymers) or chloroform-d ( $p \mathrm{CS}-\mathrm{St}$ copolymers) at room temperature. The molecular weight distribution $\left(M_{\mathrm{w}} / M_{\mathrm{n}}\right)$ and number-average molecule weight $\left(M_{\mathrm{n}}\right)$ were measured by gel permeation chromatography (GPC) on a TOSOHHLC-8220 GPC apparatus (Column: SuperHZM-Hx3) at $40{ }^{\circ} \mathrm{C}$ using tetrahydrofuran (THF) as the eluent (the flow rate was $0.35 \mathrm{~mL} / \mathrm{min}$ ) against polystyrene standard. Differential scanning calorimetry analyses were carried out on a Q 100 DSC from TA instrument under a nitrogen atmosphere. Any thermal history difference in the polymers was eliminated by first heating the specimen to above $350{ }^{\circ} \mathrm{C}$, then cooling at $10{ }^{\circ} \mathrm{C} \mathrm{min}^{-1}$ to room temperature, and finally recording the second DSC scan from 25 to $350{ }^{\circ} \mathrm{C}$ at $10{ }^{\circ} \mathrm{C} / \mathrm{min}$.

Homopolymerization of para-Chlorostyrene(Table 1, Run 11). In a glovebox, a toluene solution $(3 \mathrm{~mL})$ of complex $3(4.8 \mathrm{mg}, 10 \mu \mathrm{mol})$ and 1 equiv. of $\left[\mathrm{Ph}_{3} \mathrm{C}\right]\left[\mathrm{B}\left(\mathrm{C}_{6} \mathrm{~F}_{5}\right)_{4}\right]$ (9.2 $\mathrm{mg}, 10 \mu \mathrm{mol})$ were added to a $10 \mathrm{~mL}$ flask. The flask was placed in a bath at $-25^{\circ} \mathrm{C}$. 
Then, injected 0.6 mL $p$ CS into the flask. After the mixture had been stirred for $1 \mathrm{~h}$, methanol was injected to terminate the polymerization system. The viscous mixture was poured into a large quantity of methanol to precipitate the polymeric product, which was then collected by filtration, washed with methanol, and dried under vacuum at $40{ }^{\circ} \mathrm{C}$ to a constant weight. The conversion was calculated by weight.

Copolymerization of para-Chlorostyrene and Styrene(Table 2, Run 5). In a glovebox, a toluene solution $(3 \mathrm{~mL})$ of complex $3(4.8 \mathrm{mg}, 10 \mu \mathrm{mol})$ and 1 equiv. of $\left[\mathrm{Ph}_{3} \mathrm{C}\right]\left[\mathrm{B}\left(\mathrm{C}_{6} \mathrm{~F}_{5}\right)_{4}\right](9.2 \mathrm{mg}, 10 \mu \mathrm{mol})$ were added to a $10 \mathrm{~mL}$ flask. A mixture of $p \mathrm{CS}$ $(0.069 \mathrm{~g}, 0.5 \mathrm{mmol})$ and styrene $(0.47 \mathrm{~g}, 4.5 \mathrm{mmol})$ was added under vigorously stirring to the flask. The polymerization reaction was terminated by addition of methanol after $3 \mathrm{~min}$. The resulting mixture was poured into a large amount of methanol to precipitate the polymeric product, which was then collected by filtration, washed with methanol, and dried under vacuum at $40{ }^{\circ} \mathrm{C}$ to a constant weight.

The styrene $(\mathrm{St})$ and $p \mathrm{CS}$ contents of the $p \mathrm{CS}-\mathrm{St}$ copolymers were calculated according to the following formulas: ${ }^{3}$

St $\mathrm{mol} \%=2\left(\mathrm{I}_{2}-\mathrm{I}_{1}\right) / \mathrm{I}_{1} \times 100$

$p \mathrm{CS}$ mol $\%=100-\mathrm{St} \mathrm{mol} \%$

Where $I_{1}$ is the integration of the peaks from 6.30 to $6.65 \mathrm{ppm}$ (two aromatic protons of the styrene unit and two aromatic protons of $p \mathrm{CS}$ unit) and $\mathrm{I}_{2}$ is the integration of the peaks from 6.95 to $7.15 \mathrm{ppm}$ (three aromatic protons of the styrene unit and two aromatic protons of $p \mathrm{CS}$ unit) in the ${ }^{1} \mathrm{H}$ NMR spectrum of the $p$ CS-St copolymer. 
Terpolymerization of para-Chlorostyrene with Styrene and Butadiene (Table 3, run 2). In a glovebox, butadiene $(5 \mathrm{~mL}, 14.2 \%$ butadiene in toluene), styrene $(1.1 \mathrm{~mL})$ and $p \mathrm{CS}(0.3 \mathrm{~mL})$ were added to a $20 \mathrm{~mL}$ flash. Then, toluene solution $(5 \mathrm{~mL})$ of complex 1 (5.9 mg, $10 \mu \mathrm{mol}), 1$ equiv. of $\left[\mathrm{Ph}_{3} \mathrm{C}\right]\left[\mathrm{B}\left(\mathrm{C}_{6} \mathrm{~F}_{5}\right)_{4}\right](9.2 \mathrm{mg}, 10 \mu \mathrm{mol})$ and 10 equivalents of $\mathrm{Al}^{i} \mathrm{Bu}_{3}(0.20 \mathrm{~mL}, 0.5 \mathrm{~mol} / \mathrm{L})$ in toluene were added to the flask at room temperature. The polymerization reaction was terminated by addition of methanol after $16 \mathrm{~h}$. The resulting mixture was poured into a large amount of methanol to precipitate the polymeric product, which was then collected by filtration, washed with methanol, anddried under vacuum at $40{ }^{\circ} \mathrm{C}$ to a constant weight. The terpolymer was obtained in a yield $84.5 \%$.

\section{Reference:}

(1) Pan Y, Rong W, Jian Z, et al. Ligands Dominate Highly Syndioselective Polymerization of Styrene by Using Constrained-geometry-configuration Rare-earth Metal Precursors[J]. Macromolecules, 2012, 45(3):1248-1253.

(2) Tjaden, E. B.; Swenson, D. C.; Jordan, R. F. Organometallics 1995, 14, 371-386.

(3) Guo F, Jiao N, Jiang L, et al. Scandium-Catalyzed Syndiospecific Polymerization of Halide-Substituted Styrenes and Their Copolymerization with Styrene[J]. Macromolecules, 2017:acs.macromol.7b01668. 
Table S1. NBO analysis of the charge for each carbon in para-chlorostyrene and styrene.
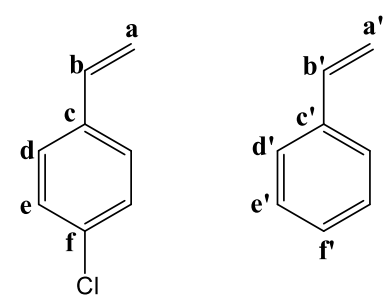

\begin{tabular}{cccccccc}
\hline Carbon & $\mathrm{a}$ & $\mathrm{b}$ & $\mathrm{c}$ & $\mathrm{d}$ & $\mathrm{e}$ & $\mathrm{f}$ & $\mathrm{sum}$ \\
\hline$p \mathrm{CS}$ & -0.349 & -0.117 & 0.175 & -0.195 & -0.128 & -0.068 & -0.99 \\
& & & & -0.179 & -0.129 & & \\
St & -0.351 & -0.190 & -0.083 & -0.181 & -0.199 & -0.201 & -1.580 \\
& & & & -0.179 & -0.196 & & \\
& & & & & &
\end{tabular}
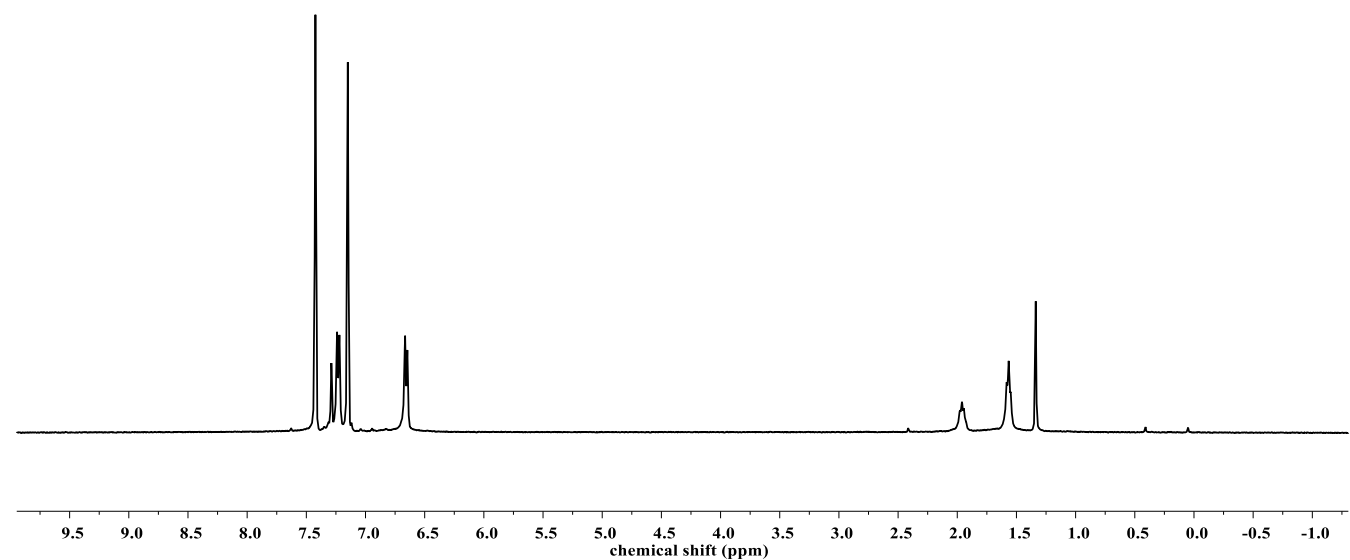

Figure S1. ${ }^{1} \mathrm{H}$ NMR spectrum $\left(400 \mathrm{MHz}, \mathrm{C}_{6} \mathrm{Cl}_{2} \mathrm{D}_{4}, 110^{\circ} \mathrm{C}\right)$ of a syndioselective $\operatorname{poly}(p \mathrm{CS})$ (Table 1, entry 13). 


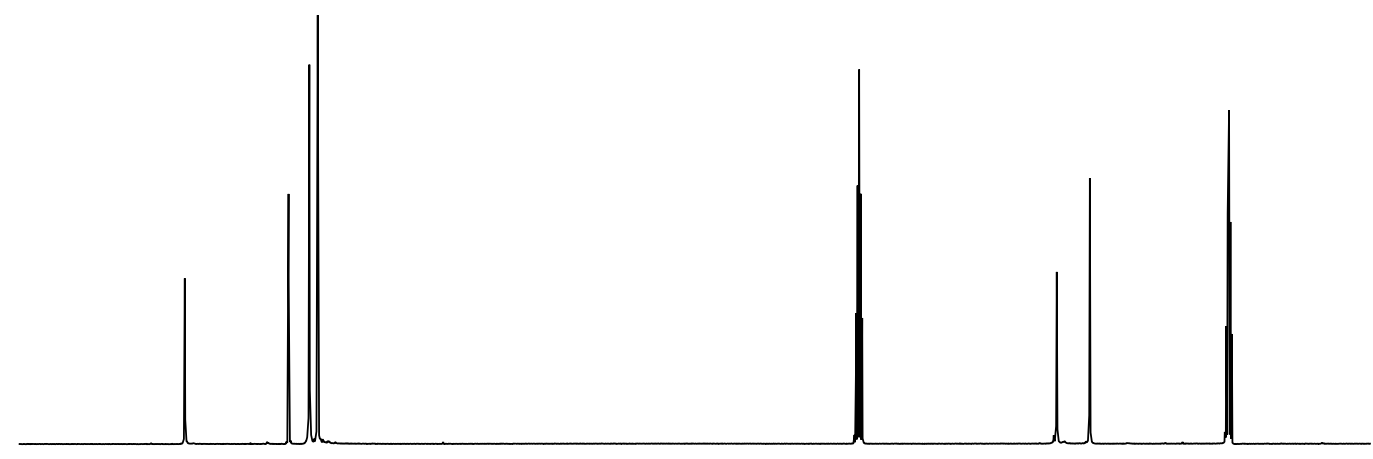

$\begin{array}{llllllllllllllllllllllllllllllllllllllll}160 & 155 & 150 & 145 & 140 & 135 & 130 & 125 & 120 & 115 & 110 & 105 & 100 & 95 & 90 & 95 & 80 & 75 & 70 & 65 & 60 & 55 & 50 & 45 & 40 & 35 & 30 & 25 & 20 & 15 & 10\end{array}$

Figure S2. ${ }^{13} \mathrm{C}$ NMR spectrum $\left(500 \mathrm{MHz}, \mathrm{C}_{4} \mathrm{D} 8 \mathrm{O}, 25^{\circ} \mathrm{C}\right)$ of a syndioselective $\operatorname{poly}(p \mathrm{CS})$ (Table 1, entry 13).

Table S2. Homopolymerizations of $p \mathrm{CS}$ in various solvents by complex $\mathbf{3}$.

\begin{tabular}{cccccccc}
\hline Solvent & $\mathrm{t}(\mathrm{h})$ & $\mathrm{Conv} .(\%)$ & $M_{\mathrm{n}}{ }^{b}\left(\times 10^{4}\right)$ & $\mathrm{PDI}^{b}$ & $T_{\mathrm{g}}{ }^{c}\left({ }^{\circ} \mathrm{C}\right)$ & $T_{\mathrm{m}}{ }^{c}\left({ }^{\circ} \mathrm{C}\right)$ & $\Delta H_{\mathrm{m}}{ }^{c}(\mathrm{~J} / \mathrm{g})$ \\
\hline $\mathrm{CH}_{2} \mathrm{Cl}_{2}$ & 72 & 0 & - & - & - & - & - \\
chlorobenzene & 0.25 & 98.3 & 3.58 & 3.25 & 127 & 324 & -17.38 \\
fluorobenzene & 24 & 66.6 & 4.76 & 4.66 & 121 & - & - \\
cyclohexane & 0.5 & 28.8 & 1.02 & 4.03 & 118 & 319 & -14.12 \\
$p$-xylene & 48 & 7.9 & 0.61 & 2.03 & 102 & 312 & -26.56 \\
benzene & 8 & 85.7 & 1.88 & 1.95 & 126 & 314 & -9.44 \\
benzene & 3 & 34.9 & 1.3 & 2.39 & 126 & 303 & -4.11 \\
$\left(60^{\circ} \mathrm{C}\right)$ & & & & & & & \\
\hline
\end{tabular}

a General polymerization conditions: scandium complex $10 \mu \mathrm{mol}$, $[\mathrm{Sc}] /\left[\mathrm{Ph}_{3} \mathrm{C}\right]\left[\mathrm{B}\left(\mathrm{C}_{6} \mathrm{~F}_{5}\right)_{4}\right]=1 / 1(\mathrm{~mol} / \mathrm{mol}), \quad$ solvent $/ p \mathrm{CS}=5 / 1(\mathrm{v} / \mathrm{v}), \quad$ polymerization temperature is $25^{\circ} \mathrm{C} .{ }^{b}$ Determined by GPC in THF at $40^{\circ} \mathrm{C}$ against polystyrene standard. ${ }^{c}$ Determined by DSC. 


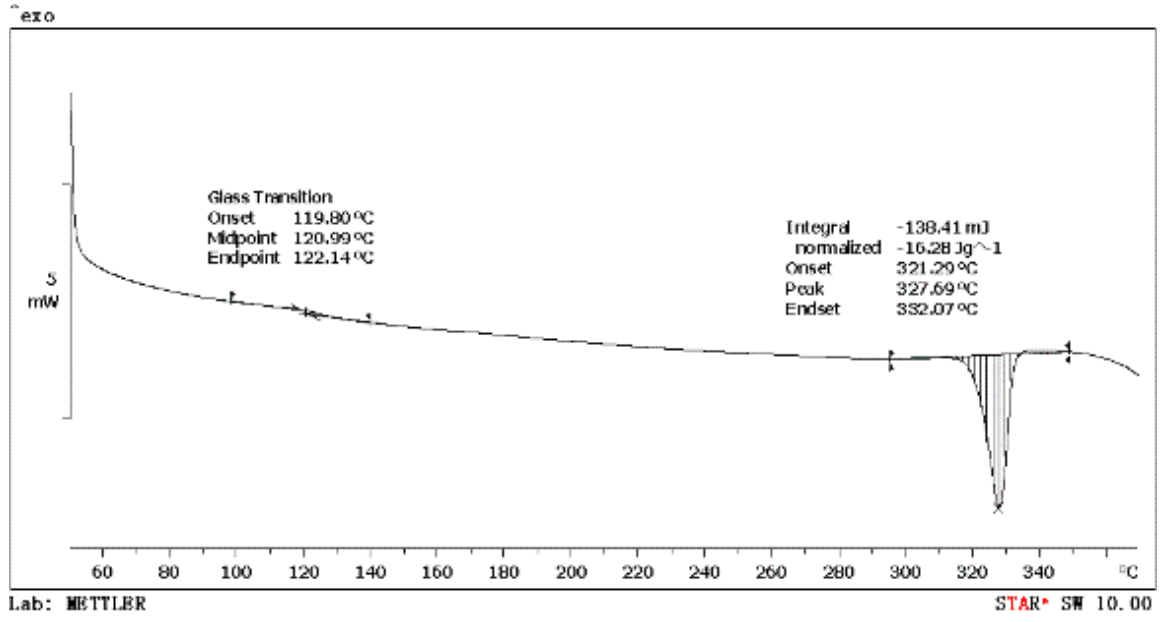

Figure S3. Representative DSC curve of syndiotactic $\mathrm{P}(p \mathrm{CS})$ (Table 1 , entry 13).

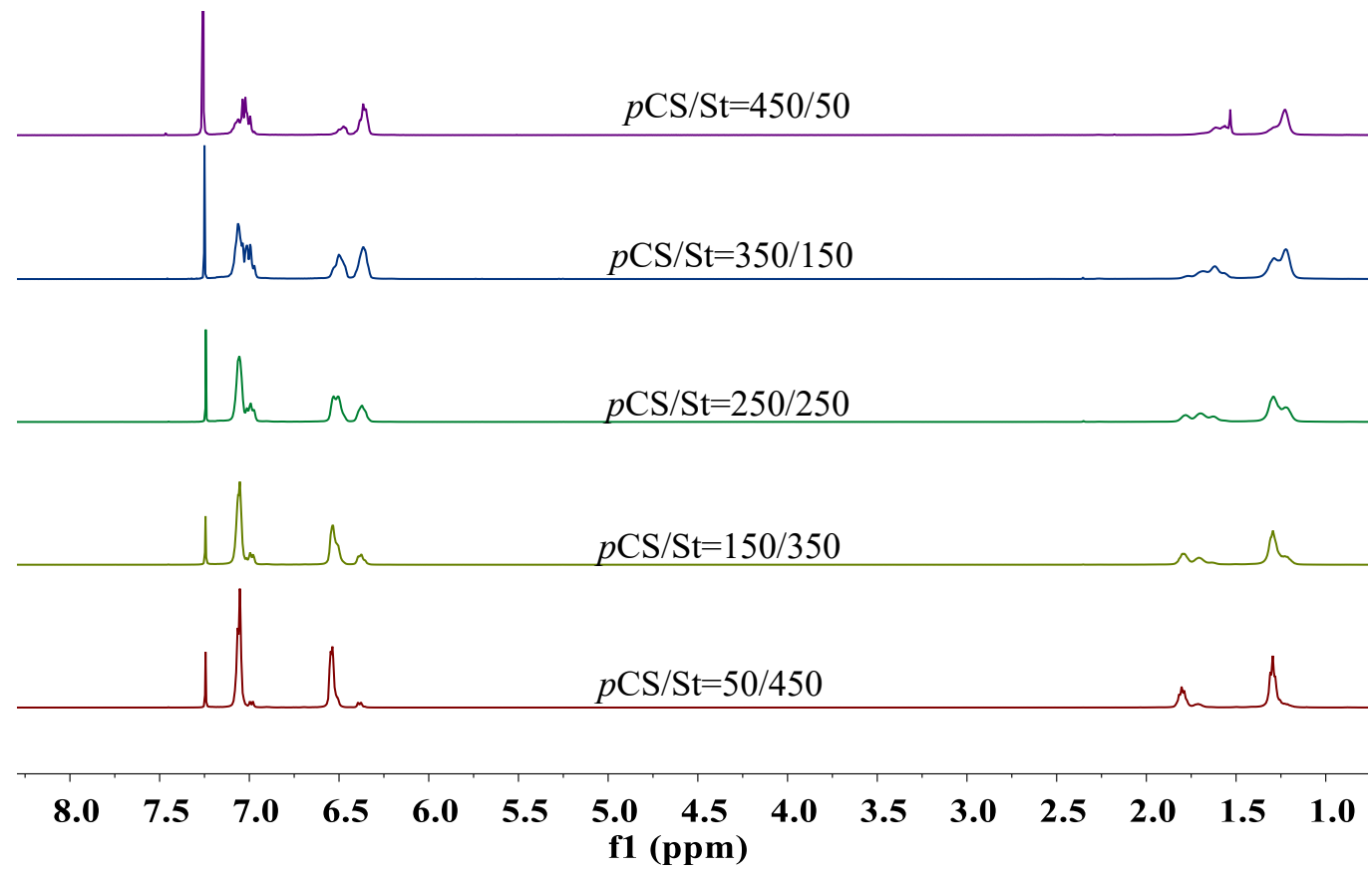

Figure S4. ${ }^{1} \mathrm{H}$ NMR spectra $\left(500 \mathrm{MHz}, \mathrm{CDCl}_{3}, 25^{\circ} \mathrm{C}\right)$ of $p$ CS-St copolymers (Table 2, runs 1-5). 


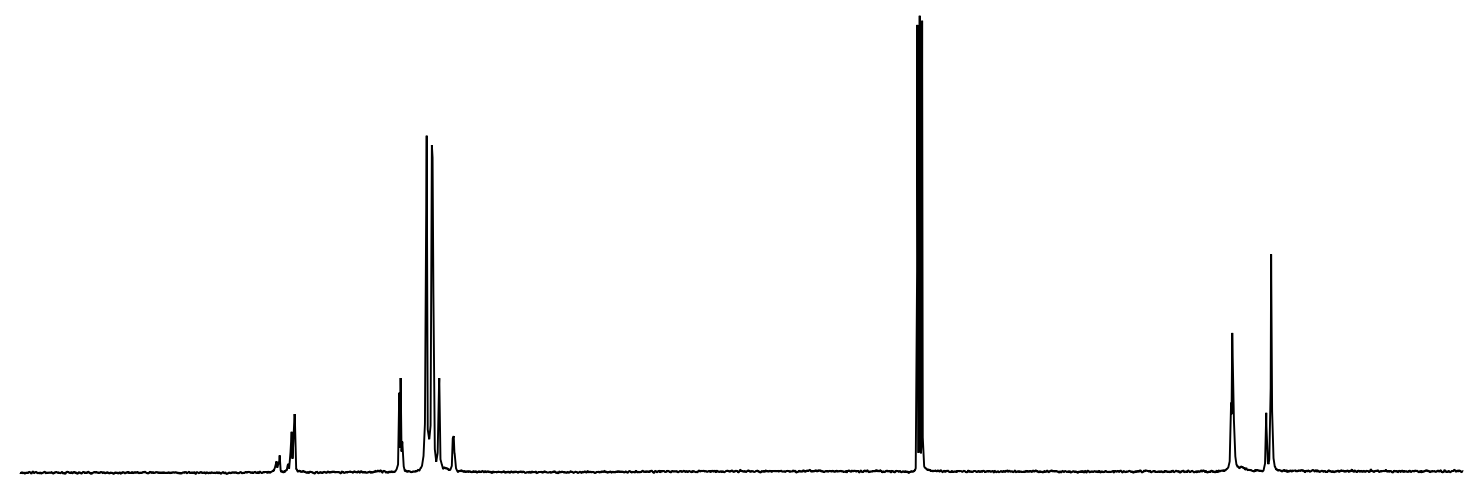

$\begin{array}{lllllllllllllllllllllllllllllllllllllllllllllllll}170 & 165 & 160 & 155 & 150 & 145 & 140 & 135 & 130 & 125 & 120 & 115 & 110 & 105 & 100 & 95 & 90 & 85 & 80 & 75 & 70 & 65 & 60 & 55 & 50 & 45 & 40 & 35 & 30 & 25\end{array}$

Figure S5. ${ }^{13} \mathrm{C}$ NMR spectrum $\left(500 \mathrm{MHz}, \mathrm{CDCl}_{3}, 25^{\circ} \mathrm{C}\right)$ of $p \mathrm{CS}$-St copolymer (Table

2 , run 1$)$.

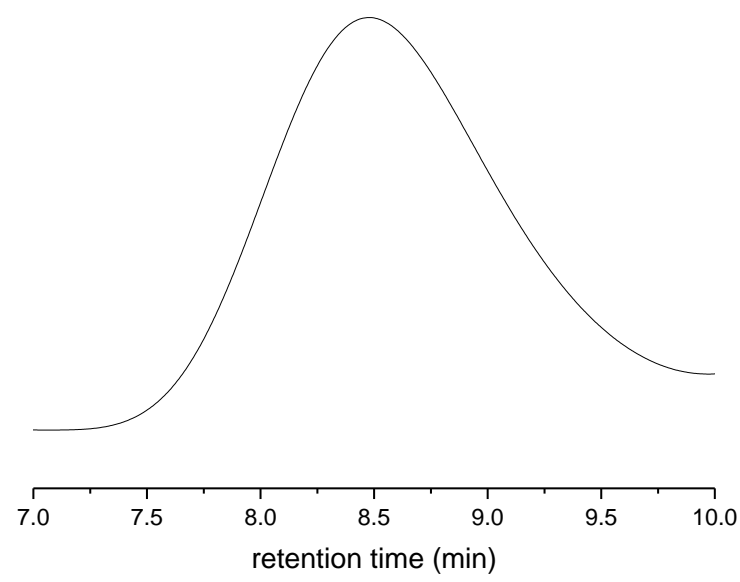

Figure S6. GPC curve of $p$ CS-St copolymer (Table 2, run 1).

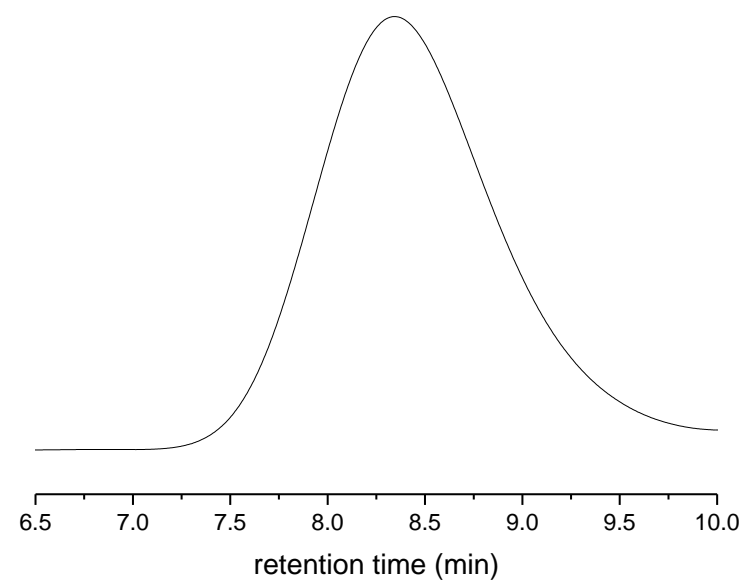

Figure S7. GPC curve of $p$ CS-St copolymer (Table 2, run 2). 


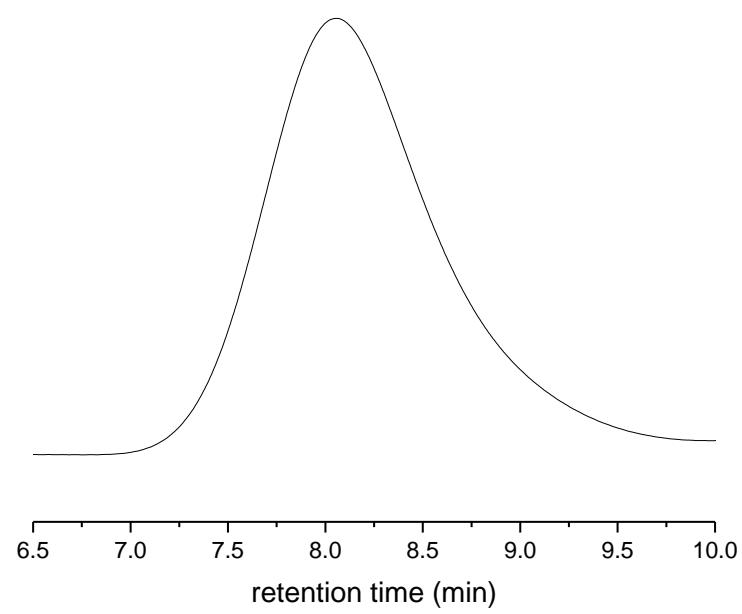

Figure S8. GPC curve of $p$ CS-St copolymer (Table 2, run 3).

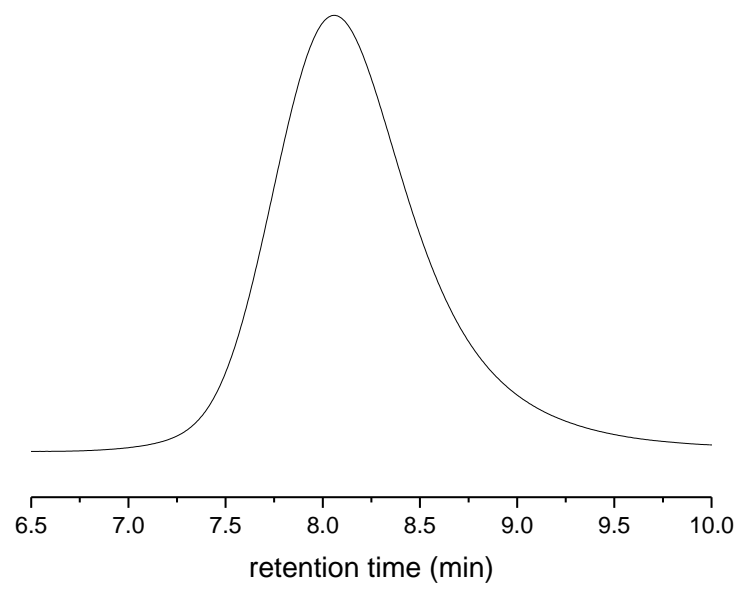

Figure S9. GPC curve of $p$ CS-St copolymer (Table 2, run 4).

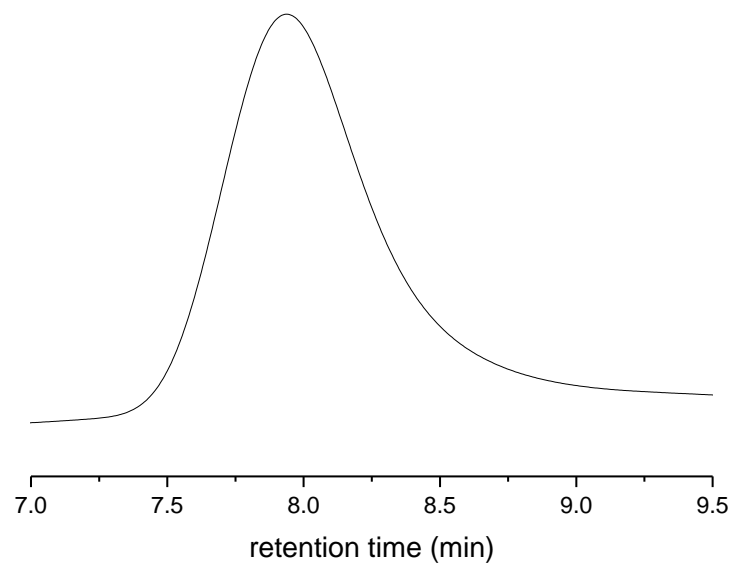

Figure S10. GPC curve of $p$ CS-St copolymer (Table 2, run 5). 
Table S3. Copolymerizations of $p \mathrm{CS}$ with styrene under low conversion $(<10 \%){ }^{a}$

\begin{tabular}{cccccc}
\hline entry & $p$ CS:St & Conv.(\%) & $p$ CS cont $(\mathrm{mol} \%)$ & $\mathrm{R}^{b}$ & $\rho^{c}$ \\
\hline 1 & $150: 834$ & 9.3 & 5.88 & 0.18 & 0.062 \\
2 & $300: 681$ & 9.8 & 14.3 & 0.44 & 0.167 \\
3 & $500: 492$ & 5.9 & 29.7 & 1.02 & 0.422 \\
4 & $600: 384$ & 5.1 & 40.2 & 1.56 & 0.672 \\
5 & $700: 303$ & 2.5 & 50 & 2.31 & 1 \\
\hline
\end{tabular}

a General polymerization conditions: $25^{\circ} \mathrm{C}$, rare earth complex $10 \mu \mathrm{mol}$, $[\mathrm{Sc}] /\left[\mathrm{Ph}_{3} \mathrm{C}\right]\left[\mathrm{B}\left(\mathrm{C}_{6} \mathrm{~F}_{5}\right)_{4}\right] \quad=1 / 1(\mathrm{~mol} / \mathrm{mol}), \quad 10 \mathrm{~mL} \quad$ toluene. $\quad{ }^{b} \quad \mathrm{R}=\left[\mathrm{M}_{p \mathrm{Cs}}\right] /[\mathrm{Mst}]$. $\rho=\mathrm{d}\left[\mathrm{M}_{p \mathrm{CS}}\right] / \mathrm{d}\left[\mathrm{M}_{\mathrm{St}}\right]$

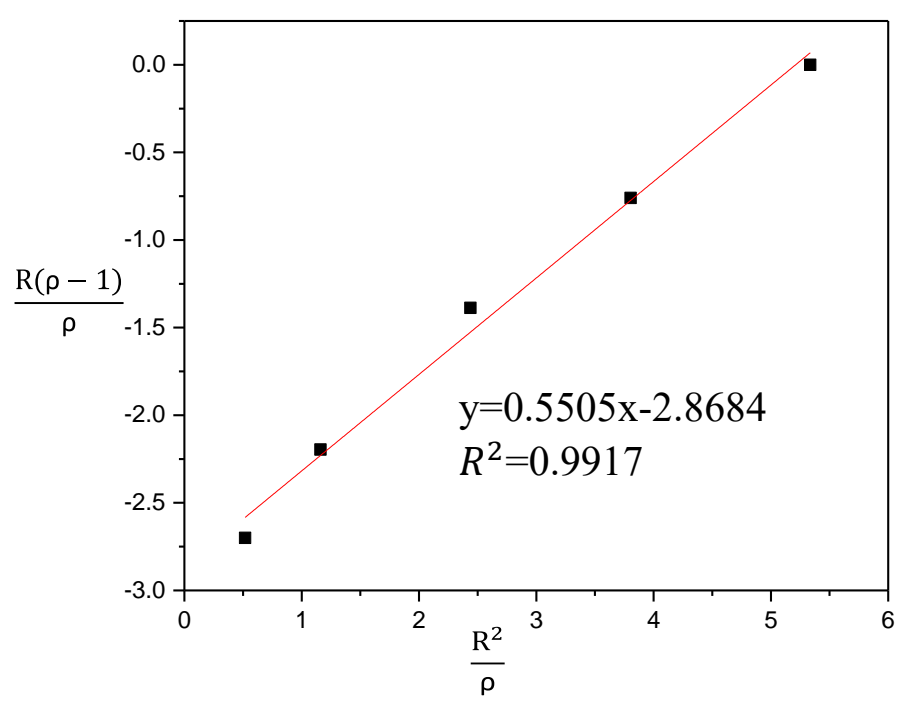

Figure S11. The reactivity ratio of styrene and para-chlorostyrene and least-squares best fit line.

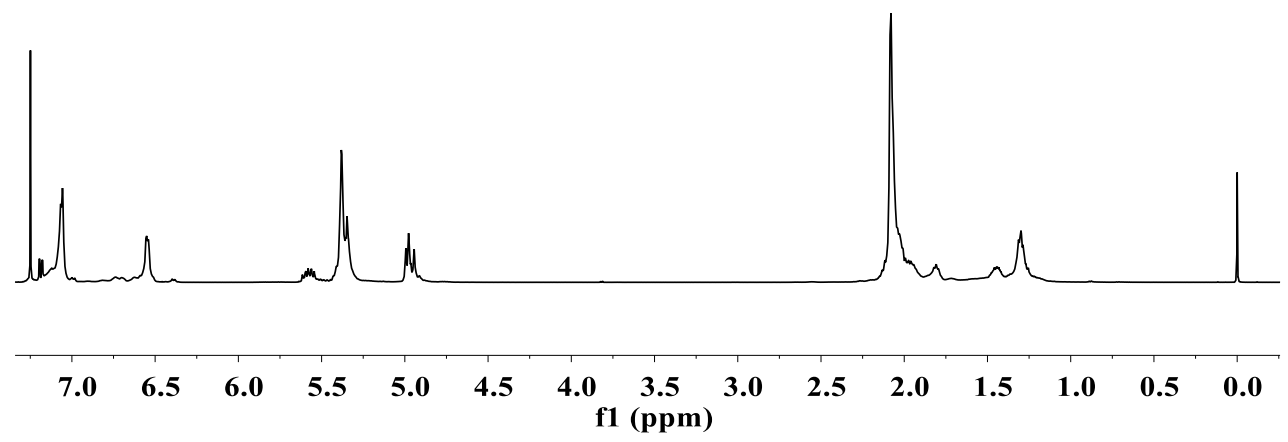

Figure S12. ${ }^{1} \mathrm{H}$ NMR spectrum $\left(500 \mathrm{MHz}, \mathrm{CDCl}_{3}, 25^{\circ} \mathrm{C}\right)$ of $p \mathrm{CS}-\mathrm{St}-\mathrm{BD}$ terpolymer (Table 3, run 4). 


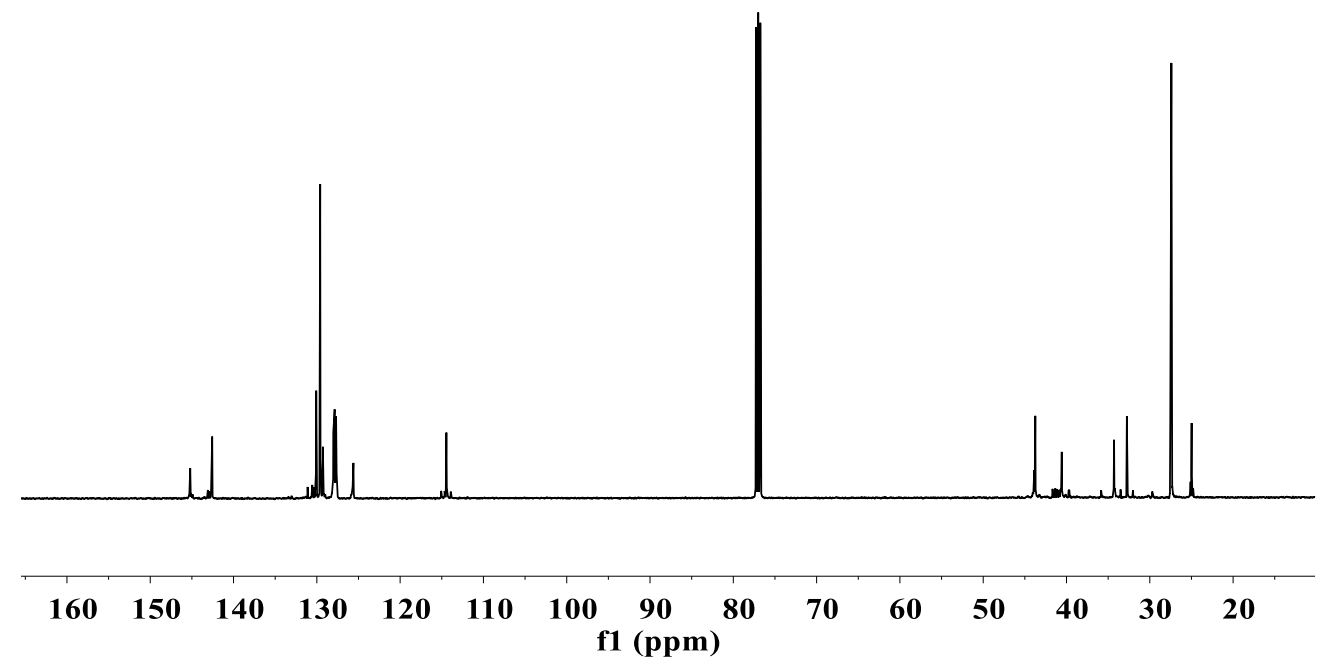

Figure S13. ${ }^{13} \mathrm{C}$ NMR spectrum $\left(500 \mathrm{MHz}, \mathrm{CDCl}_{3}, 25^{\circ} \mathrm{C}\right)$ of $p \mathrm{CS}-\mathrm{St}-\mathrm{BD}$ terpolymer (Table 3, run 4). 